\title{
Hierarchical Manganese Oxide/Carbon Nanocomposites for Supercapacitor Electrodes
}

\author{
Yiting Peng ${ }^{1,2,}$, Zheng Chen ${ }^{2, \S}$, Jing Wen ${ }^{2}$, Qiangfeng Xiao ${ }^{2}$, Ding Weng ${ }^{2}$, Shiyu He ${ }^{1}(\bowtie)$, Hongbin Geng ${ }^{1}(\bowtie)$, \\ and Yunfeng $\operatorname{Lu}^{2}(\bowtie)$ \\ ${ }^{1}$ Department of Materials Science and Engineering, Harbin Institute of Technology, Harbin, 150001, China \\ ${ }^{2}$ Department of Chemical and Biomolecular Engineering, University of California, Los Angeles, CA 90095, USA \\ Received: 14 October 2010 / Revised: 5 November 2010 / Accepted: 6 November 2010 \\ (C) Tsinghua University Press and Springer-Verlag Berlin Heidelberg 2010
}

\begin{abstract}
$\mathrm{MnO}_{2} /$ carbon nanocomposites with hierarchical pore structure and controllable $\mathrm{MnO}_{2}$ loading have been synthesized using a self-limiting growth method. This was achieved by the redox reactions of $\mathrm{KMnO}_{4}$ with sacrificed carbon substrates that contain hierarchical pores. The unique pore structure allows the synthesis of nanocomposites with tunable $\mathrm{MnO}_{2}$ loading up to $83 \mathrm{wt} . \%$. The specific capacitance of the nanocomposites increased with the $\mathrm{MnO}_{2}$ loading; the conductivity measured by electrochemical impedance spectroscopy, on the other hand, decreased with increasing $\mathrm{MnO}_{2}$ loading. Optimization of the $\mathrm{MnO}_{2}$ loading resulted in nanocomposites with high specific capacitance and excellent rate capability. This work provides important fundamental understanding which will facilitate the design and fabrication of high-performance supercapacitor materials for a large variety of applications.
\end{abstract}

\section{KEYWORDS}

Hierarchically porous carbon, $\mathrm{MnO}_{2} /$ carbon nanocomposite, supercapacitor

\section{Introduction}

Supercapacitors are emerging as a class of high-power energy-storage devices [1-4]; their broader uses, however, are still limited by their energy density [5-7]. Generally, a supercapacitor is based on the electrical double layers formed along carbon electrodes, which may provide capacitance of up to $300 \mathrm{~F} / \mathrm{g}$ in an aqueous electrolyte [8, 9]. Oxides of transition metals, such as $\mathrm{RuO}_{2}$ [10-12], $\mathrm{MnO}_{2}$ [13-16], $\mathrm{NiO}$ [17, 18], $\mathrm{Co}_{3} \mathrm{O}_{4}[19]$, and $\mathrm{V}_{2} \mathrm{O}_{5}[20,21]$, possess significantly higher capacitances; however, harvesting such capacitance has been limited by their low conductivity and redox kinetics. To address such intrinsic limitations, a common strategy is to integrate low-dimensional oxide materials with conductive components, such as carbon, which has led to the development of various nanocomposites with significantly improved energy density [22-24]. Nevertheless, many essential questions about such composites, such as how the structure, composition and interfaces of the composites may affect the capacitive performance, remain open.

We report herein the synthesis of $\mathrm{MnO}_{2} /$ carbon nanocomposites with controlled structure and composition and the study of the role of these properties in determining capacitive performance. $\mathrm{MnO}_{2}$ is currently

$\S$ These authors contributed equally.

Address correspondence to Shiyu He, syhe@21cn.com; Hongbin Geng, genghb@yahoo.com; Yunfeng Lu, luucla@ucla.edu 
considered as one of the most promising redox components for supercapacitor applications owning to its high capacitance, low cost, and low toxicity. To date, various $\mathrm{MnO}_{2} /$ carbon composites have been synthesized, such as composites with planar graphite [25], acetylene black [26, 27], ordered mesoporous carbon [28, 29], carbon nanotubes [30-33], and carbon aerogels and nanofoams [34]. These have generally been synthesized by physical mixing of $\mathrm{MnO}_{2}$ with carbon [31], or electrochemically or chemically depositing $\mathrm{MnO}_{2}$ on carbon substrates [32, 33]. Among these synthesis methods, the chemical deposition of $\mathrm{MnO}_{2}$ through self-limiting redox reactions of $\mathrm{KMnO}_{4}$ and carbon is of particular interest [25-29]. In such a synthesis, carbon substrates are exposed to $\mathrm{KMnO}_{4}$ solution at room temperature or an elevated temperature, and a spontaneous redox reaction described as

$$
4 \mathrm{MnO}_{4}^{-}+3 \mathrm{C}+2 \mathrm{H}_{2} \mathrm{O} \longrightarrow 4 \mathrm{MnO}_{2}+3 \mathrm{CO}_{2}+4 \mathrm{OH}^{-}
$$

occurs producing $\mathrm{MnO}_{2}$ on the sacrificial carbon substrates [35]. The resulting $\mathrm{MnO}_{2}$ layer reduces the diffusion of the $\mathrm{MnO}_{4}^{-}$ions, generating conformal $\mathrm{MnO}_{2}$ coatings on the conductive carbon substrates. Such a self-limiting growth confers several major advantages, such as intimate interfaces between the oxide and the carbon, nanosized oxide particles, and controllable oxide thickness.

Nevertheless, the structure and composition of such $\mathrm{MnO}_{2} /$ carbon composites are governed by transport of the $\mathrm{KMnO}_{4}$ in solution and its reaction with carbon, which is very rapid even at room temperature. Note that the diffusion of $\mathrm{KMnO}_{4}$ in porous carbon substrates, such as activated carbon and mesoporous carbons, is generally slow in comparison with the fast reaction kinetics $[36,37]$. The rapid reactions result in the preferential formation of $\mathrm{MnO}_{2}$ layers located on the exterior of the carbon substrates, blocking inwards diffusion and reaction of $\mathrm{KMnO}_{4}$. This technical difficulty inevitably leads to a low $\mathrm{MnO}_{2}$ loading in the composites, which is detrimental for overall capacitance. Moreover, the formation of $\mathrm{MnO}_{2}$ is often associated with reduced pore accessibility and electron conductivity. In fact, it has been observed that increasing the oxide loading in such carbon composites by further promoting the redox reaction resulted in a reduction in the overall capacitance [38]. Therefore, the synthesis of $\mathrm{MnO}_{2} /$ carbon composites with higher oxide loading and controlled pore structure for fast transport of ions, which retain the carbon framework needed for electron conductivity is essential to ensure a satisfactory capacitance performance.

To address this challenge, carbon substrates with hierarchical pores (pores with multiple-length-scale diameters) rather than uniform pores were used in this work. The presence of large pores ensures the effective transport of $\mathrm{KMnO}_{4}$ to the substrate interior, while the mesopores provide high surface area for effective reaction. Such a structure allows the formation of composites with high oxide loadings that are homogenously and intimately coated on the sacrificial carbon scaffold. Moreover, the resulting nanocomposites still retain an interconnected porous structure, which facilitates effective electrolyte diffusion and charge transport and ensures higher specific capacitance and better rate capability. Resulting from this unique design, nanocomposites with $\mathrm{MnO}_{2}$ loadings of up to $80 \mathrm{wt} . \%$ have been achieved, which is a significant advance on the current state of the art. For the first time, electrochemical impedance spectroscopy has been used to study the synergic effects between the $\mathrm{MnO}_{2}$ mass loading and conductive carbon scaffold, providing insights leading to better capacitance performance.

\section{Experimental}

\subsection{Synthesis of carbon substrate and $\mathrm{MnO}_{2} /$ carbon nanocomposites}

The porous carbon substrates were synthesized by an assembly process using phenolic resol as the carbon precursor. Tri-block copolymer F127 $(\mathrm{Mw}=$ 12,600, $\mathrm{PEO}_{106} \mathrm{PPO}_{70} \mathrm{PEO}_{106}$, where PEO and PPO are poly(ethylene oxide) and poly(propylene oxide), respectively) was used as a soft template; silicate clusters formed by hydrolysis and condensation reactions of tetraethyl orthosilicate (TEOS) and colloidal silica particles (70-100 $\mathrm{nm}$ in diameter) were used as the hard template. Briefly, F127 (1.6 g), $0.2 \mathrm{~mol} / \mathrm{L} \mathrm{HCl}$ $(1.0 \mathrm{~g})$, ethanol $(8 \mathrm{~g})$, TEOS $(2.08 \mathrm{~g})$, and colloidal silica $(1.5 \mathrm{~g})$ were mixed in a flask and vigorously stirred 
for $4 \mathrm{~h}$. The mixture was transferred to a glass dish and after evaporation of the solvent for $12 \mathrm{~h}$ at room temperature, the mixture was put into an oven at $100{ }^{\circ} \mathrm{C}$ for $24 \mathrm{~h}$ to effect the thermo-polymerization. The samples were then carbonized in a tubular furnace under nitrogen flow. The samples were heated from room temperature to $350{ }^{\circ} \mathrm{C}$ at $2{ }^{\circ} \mathrm{C} / \mathrm{min}$, kept at $350{ }^{\circ} \mathrm{C}$ for $2 \mathrm{~h}$ and heated to $500{ }^{\circ} \mathrm{C}$ at $1{ }^{\circ} \mathrm{C} / \mathrm{min}$, followed by heating to $900{ }^{\circ} \mathrm{C}$ at $10{ }^{\circ} \mathrm{C} / \mathrm{min}$ and holding at $900{ }^{\circ} \mathrm{C}$ for $2 \mathrm{~h}$. After carbonization, the as-formed carbon/silica composites were soaked with $5 \mathrm{wt} . \% \mathrm{HF}$ for $12 \mathrm{~h}$ to remove the silica, converting the composites into hierarchical porous carbons. For comparison, ordered mesoporous carbon (OMC) with a uniform pore structure was also synthesized according to the method reported by Zhao et al. [39].

The synthesis of $\mathrm{MnO}_{2} /$ carbon composites was conducted by a procedure adapted from the Ref. [25]. Briefly, $0.08 \mathrm{~g}$ of carbon substrate was soaked in $25 \mathrm{~mL}$ of $\mathrm{Na}_{2} \mathrm{SO}_{4}$ solution $(0.1 \mathrm{~mol} / \mathrm{L})$ at $50{ }^{\circ} \mathrm{C}$ in vacuum and stirred with $25 \mathrm{~mL}$ solution containing $0.1 \mathrm{~mol} / \mathrm{L}$ $\mathrm{KMnO}_{4}$ and $0.1 \mathrm{~mol} / \mathrm{L} \mathrm{Na}_{2} \mathrm{SO}_{4}$ for 1, 5, 10, 30, 60, 120, or $240 \mathrm{~min}$. The products were then washed with deionized water and dried at $80{ }^{\circ} \mathrm{C}$ in vacuum for $24 \mathrm{~h}$; the products are denoted $\mathrm{MnO}_{2} /$ carbon-time (e.g., $\mathrm{MnO}_{2} /$ carbon-240).

\subsection{Material and electrode characterization}

X-ray diffraction patterns were recorded on a PANalytical X'Pert Pro X-ray powder diffractometer using copper $K \alpha$ radiation $(\lambda=1.54 \AA)$. Nitrogen sorption isotherms were measured at $77 \mathrm{~K}$ with a Micromeritics ASAP 2020 analyzer. The samples were degassed in vacuum at $180{ }^{\circ} \mathrm{C}$ for $3 \mathrm{~h}$ before measurements were taken. The specific surface areas were calculated by the Brunauer-Emmett-Teller (BET) method using the adsorption branch in the relative pressure range from 0.04 to 0.25 . The pore size distributions $\left(D_{\mathrm{p}}\right)$ were derived from the adsorption branch using the Barrett-Joyner-Halenda (BJH) model. Thermogravimetric analysis (TGA) was carried out in a PerkinElmer analyzer from $25^{\circ} \mathrm{C}$ to $800{ }^{\circ} \mathrm{C}$ with a heating rate of $10^{\circ} \mathrm{C} / \mathrm{min}$ and air flow rate of $100 \mathrm{~mL} / \mathrm{min}$. Scanning electron microscopy (SEM) images were obtained using a JEOL JSM-6700 FE-SEM.
Transmission electron microscopy (TEM) images were obtained using a Philips CM120 microscope operated at $120 \mathrm{kV}$. High-resolution transmission electron microscopy (HRTEM) experiments were conducted on a Titan $300 \mathrm{kV} \mathrm{S} /$ TEM operated at $300 \mathrm{kV}$.

The electrodes were assembled on nickel foam collectors. Briefly, $80 \mathrm{wt} . \%$ of the test material, $10 \mathrm{wt} . \%$ of carbon black, and $10 \mathrm{wt} . \%$ of poly(vinylidene fluoride) dispersed in $\mathrm{N}$-methylpyrrolidinone were mixed to form a slurry. The slurry was ultrasonically treated at $60^{\circ} \mathrm{C}$ for $0.5 \mathrm{~h}$, coated on a nickel foam substrate, and dried at $80^{\circ} \mathrm{C}$ for $10 \mathrm{~min}$ under vacuum. As formed electrodes were then subjected to a pressure of $2 \mathrm{MPa}$ and further dried under vacuum at $100{ }^{\circ} \mathrm{C}$ for $12 \mathrm{~h}$. The electrochemical measurements were conducted using a Solartron 1860 electrochemistry workstation. Cyclic voltammetry measurements were conducted in $1 \mathrm{~mol} / \mathrm{L} \mathrm{Na}_{2} \mathrm{SO}_{4}$ aqueous solution at room temperature using a platinum wire as the counter electrode and an $\mathrm{Ag} / \mathrm{AgCl}$ electrode as the reference electrode. Electrochemical impedance spectroscopy (EIS) measurements were conducted on a Solartron 1287 using a sinusoidal signal with an AC voltage of $13 \mathrm{mV}$ amplitude in the frequency range from $1 \times 10^{5}$ to $1 \times 10^{-2} \mathrm{~Hz}$. The specific capacitance $(C)$ of the electrode materials were derived using the equation $C=I /(\mathrm{d} E / \mathrm{d} t) \approx I /(\Delta E / \Delta t)$, where $I$ is the constant discharge current density, $E$ is the cell voltage, and $\mathrm{d} E / \mathrm{d} t$ is the slope of the discharge curve.

\section{Results and discussion}

\subsection{Composition and structure of the composites}

The structure and composition of the nanocomposites were found to depend strongly on the reaction conditions. Figure 1(a) compares the TGA traces of the carbon substrate and a representative composite synthesized using $0.1 \mathrm{~mol} / \mathrm{L} \mathrm{KMnO}_{4}$ at $50{ }^{\circ} \mathrm{C}$ with a reaction time of $120 \mathrm{~min}$ (denoted as $\mathrm{MnO}_{2} /$ carbon-120). The carbon substrate lost $99.7 \%$ of its mass at $640{ }^{\circ} \mathrm{C}$, while the TGA curve of $\mathrm{MnO}_{2} /$ carbon-120 can be divided into three regions. The mass loss $(\sim 15 \%)$ below $200{ }^{\circ} \mathrm{C}$ can be ascribed to the removal of adsorbed water. It is worth mentioning that the mass loss for $\mathrm{MnO}_{2} /$ carbon-10 in this region was slightly less ( 11\%) 


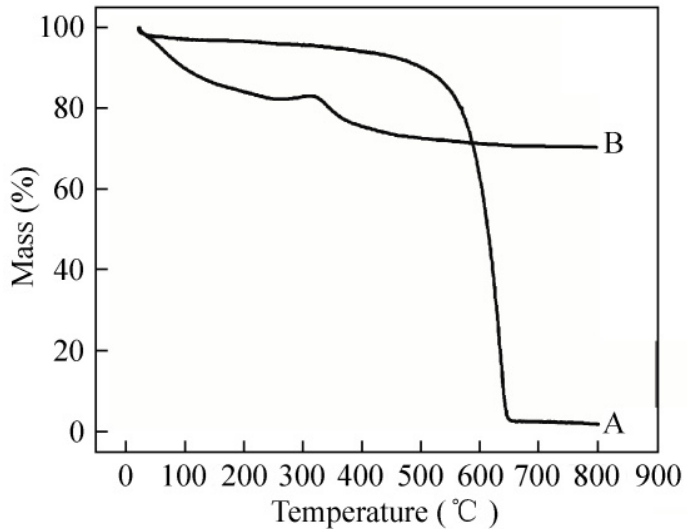

(a)

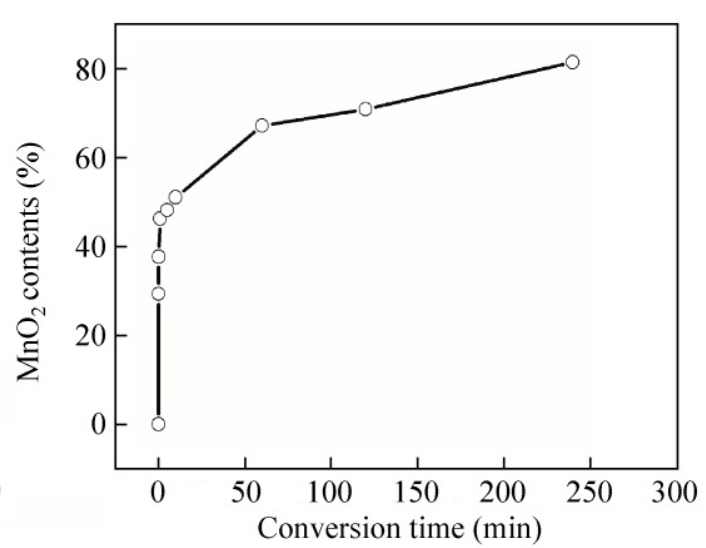

(b)

Figure 1 (a) Thermogravimetric analysis (TGA) curves of (A) the carbon substrate and (B) $\mathrm{MnO}_{2} /$ carbon-120 in air (100 mL/min). (b) Dependence of the $\mathrm{MnO}_{2}$ content on the reaction time of the carbon substrates with $\mathrm{KMnO}_{4}$ solution as measured by TGA

(Fig. S-1 in the electronic supplementary material (ESM)), which is due to its thinner $\mathrm{MnO}_{2}$ coating that retains less interlayer hydration [40]. The mass loss between $200{ }^{\circ} \mathrm{C}$ and $400{ }^{\circ} \mathrm{C}$ corresponds to the combustion of residual carbon catalyzed by $\mathrm{MnO}_{2}$ and its derivatives [41]. At the same time, the layered structure transformed to a thermodynamically stable tunnel structure [42, 43], and in addition $\delta-\mathrm{MnO}_{2}$ decomposed to $\mathrm{Mn}_{3} \mathrm{O}_{4}$ with release of oxygen at around $400{ }^{\circ} \mathrm{C}$, which also contributed to the mass loss. Above $500{ }^{\circ} \mathrm{C}$, residual carbon underwent combustion and $\mathrm{Mn}_{3} \mathrm{O}_{4}$ was transformed to $\mathrm{Mn}_{2} \mathrm{O}_{3}$ [44].

Based the TGA analysis, the $\mathrm{MnO}_{2}$ contents of the composites synthesized with reaction times of $1,5,10$, 30, 60, 120, and $240 \mathrm{~min}$ are compared in Fig. 1(b). It was found that the $\mathrm{MnO}_{2}$ content increased rapidly to $46 \mathrm{wt} . \%$ within minutes and more slowly subsequently, due to the self-limiting growth mechanism, reaching 67 and $83 \mathrm{wt} . \%$ after $60 \mathrm{~min}$ and $240 \mathrm{~min}$ of the reaction respectively. The rapid formation of $\mathrm{MnO}_{2}$ can be attributed to the large carbon $/ \mathrm{KMnO}_{4}$ contact area and rapid $\mathrm{KMnO}_{4}$ diffusion and reaction kinetics. Composites with 83 wt.\% of $\mathrm{MnO}_{2}$ were obtained; this is significantly higher than those prepared using mesoporous carbon or activated carbon as the sacrificed substrates ( 40 wt.\%) [34].

To be best of our knowledge, this content is higher than that of materials prepared using other carbon scaffolds [29, 31].

The structure of the composites was characterized using SEM, TEM, X-ray diffraction (XRD), and other techniques. Figure 2(a) shows a representative SEM image of the hierarchical carbon substrate showing the presence of macropores with diameter from $70-100 \mathrm{~nm}$. Their mesoporous structure is clearly revealed under TEM observation (Fig. 2(c)). These mesoporous channels have uniform diameters in the range $6-8 \mathrm{~nm}$, which is consistent with the use of F127 surfactant as the template [45]. Upon reaction with $\mathrm{KMnO}_{4}$ for $120 \mathrm{~min}$, the composite exhibited a rougher morphology whilst retaining the macroporous structure, and deposition of $\mathrm{MnO}_{2}$ particles was also observed (Fig. 2(b)). TEM images (Fig. 2(d)) confirmed the retention of macropores necessary for effective electrolyte transport; the ordered carbon mesoporous texture was destroyed; however, and disordered pores are clearly present in the composite. A HRTEM image (Fig. 2(d)) suggests that the $\mathrm{MnO}_{2}$ in the composites is polycrystalline, which is confirmed by XRD (Fig. S-2 in the ESM). The diffraction peaks in this figure marked Bir (birnessite) and Bur (buserite) are characteristic of two different types of layered $\delta-\mathrm{MnO}_{2}$ [46]: the sharp peaks occur at $2 \theta$ values of $12.5^{\circ}(002)$ and $25^{\circ}$ (212) can be assigned to Na-birnessite and the peak at a $2 \theta$ value of $17^{\circ}$ to Na-buserite, with these layered structures having an interlayer separation of $0.7 \AA$ and $1 \AA$, respectively [47]. The reflection marked Feit at a $2 \theta$ value of $19.1^{\circ}$ (002) represents feitknechtite $(\beta-\mathrm{MnOOH})$ derived from a phase transformation which depends on the $\mathrm{MnO}_{4}^{-} / \mathrm{Mn}^{2+}$ ratio [48]. 


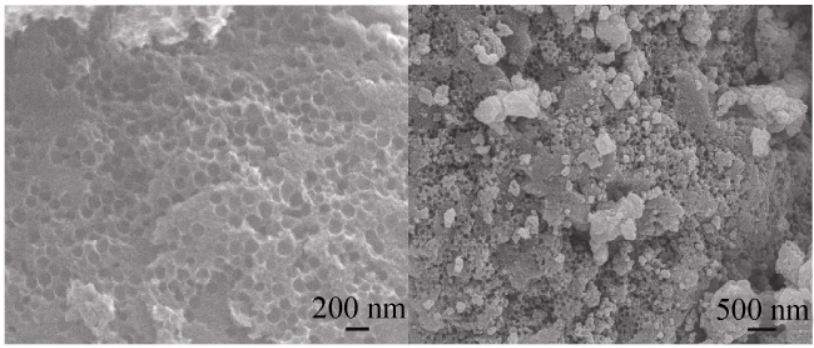

(a)

(b)

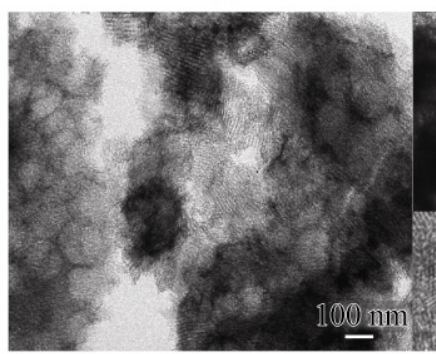

(c)

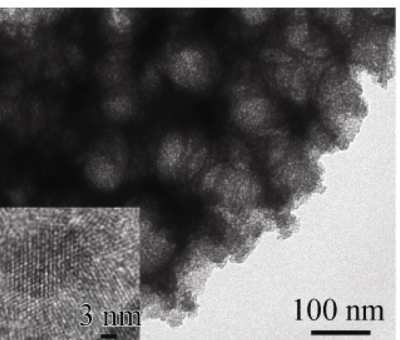

(d)

Figure 2 SEM images of (a) the carbon substrate and (b) $\mathrm{MnO}_{2} /$ carbon-120; TEM images of (c) the carbon substrate and (d) $\mathrm{MnO}_{2} /$ carbon-120 (inset, high-resolution TEM of the $\mathrm{MnO}_{2}$ within the composite)

The pore structure of the nanocomposites was further probed using the nitrogen sorption technique. Figure 3(a) shows the nitrogen sorption isotherms and pore size distribution of the carbon substrate, clearly suggesting a hierarchical pore structure. The significant nitrogen uptake at relative pressures below 0.3 is consistent with the microporous to mesoporous structure (2-3 $\mathrm{nm}$ in pore diameter) created by removal of silicate clusters [49]. In addition, the isotherm curves show two substantial hysteresis loops which confirm the bimodal porosity in the meso- and macro- range, which are associated with mesoporous channels templated by the F127 surfactant and macropores templated by the silica colloids, respectively. For comparison, $\mathrm{MnO}_{2}$ /carbon-120 shows significantly different isotherms (Fig. 3(b)). The uptake at low relative pressure is significantly lower, suggesting a reduced microporosity and mesoporosity; significant uptake at high relative pressure $\left(P / P_{0}\right)$ is still retained, suggesting retention of the macroporosity. In particular, the presence of the hysteresis loop concluding at a relative pressure of 0.8 indicates that the macropores are connected through a mesoporous network, forming hierarchically connected pore channels.

The above studies confirm the successful synthesis of $\mathrm{MnO}_{2} /$ carbon nanocomposites with a hierarchically porous network and tunable oxide content. The relationship between the exact location of the carbon and the oxide within the nanocomposites is unclear. Since the redox reaction was initiated from the pore surface of the carbon substrates, the rapid reaction resulted in the carbon framework becoming wrapped with a layer of $\mathrm{MnO}_{2}$. Such a reaction may create porous nanocomposites in which the frameworks possess a "cable-like" structure made with a residual carbon core and an oxide exterior layer. Such a structure will be highly beneficial for harvesting the capacitance of the oxide; however, it is difficult to observe directly using electron microscopy and other techniques.

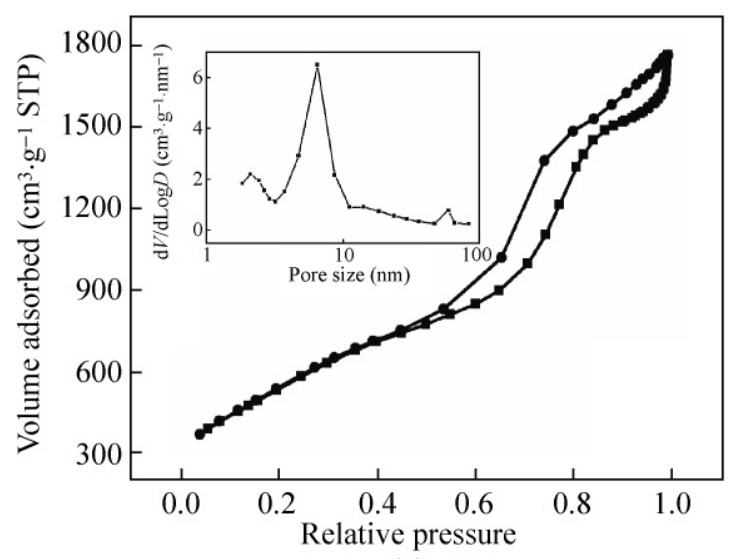

(a)

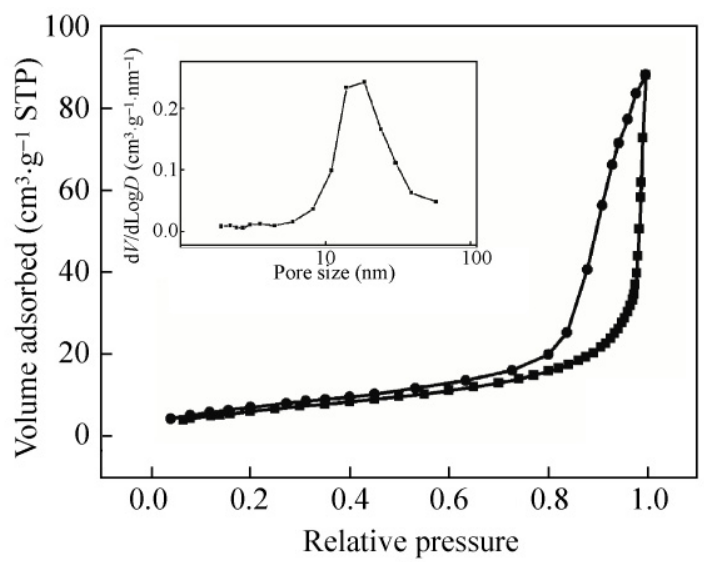

(b)

Figure 3 Nitrogen sorption isotherms and pore size distributions (insets) of (a) the hierarchical carbon substrate and (b) $\mathrm{MnO}_{2} / \mathrm{carbon}^{-120}$ nanocomposite 


\subsection{Capacitive performance of $\mathrm{MnO}_{2} /$ carbon nanocomposites}

The synthesis of $\mathrm{MnO}_{2} /$ carbon nanocomposites with a hierarchically porous network and tunable oxide content provides a unique material platform for a study of capacitance. Figure 4(a) shows the cyclic voltammetry $(\mathrm{CV})$ curves of the carbon electrode. $\mathrm{CV}$ curves with nearly symmetrical rectangular shape were observed at potential scan rates of 5,10 , and $20 \mathrm{mV} / \mathrm{s}$, owning to the connective pore structure and good conductivity. The $\mathrm{MnO}_{2} /$ carbon-120 electrode showed an obvious polarization, indicated by the distorted $\mathrm{CV}$ curve as the scan rate was increased to $20 \mathrm{mV} / \mathrm{s}$ (Fig. 4(b)). The polarization is believed to be due to the increased electron and transport resistance mentioned above. Nevertheless, with a mass loading of $70 \mathrm{wt} . \% \mathrm{MnO}_{2}$, the specific capacitance increased to $218 \mathrm{~F} / \mathrm{g}$ at a current density of $0.1 \mathrm{~A} / \mathrm{g}$, which was three times of that of the carbon substrate (Figs. 4(c) and $4(\mathrm{~d}))$.

It is well known that the capacitance generally decreases with increasing current density due to the polarization from electrolyte transport, ion diffusion or charge transfer [50,51]. To investigate the relation between the rate capability and the oxide content, galvanostatic charge and discharge (GC) tests at various current densities were conducted (Fig. 5). Owing to the favorable pore connectivity and good conductivity, the carbon electrode retained $81 \%$ (a decrease from $71 \mathrm{~F} / \mathrm{g}$ to $58 \mathrm{~F} / \mathrm{g}$ ) of its capacitance as the current density was increased from 0.1 to $2 \mathrm{~A} / \mathrm{g}$. After introducing the oxide with its high specific capacitance, the nanocomposites exhibited improved capacitance. For example, the $\mathrm{MnO}_{2} /$ carbon- 5 electrode, with 48 wt. $\% \mathrm{MnO}_{2}$ content, gave a moderate specific

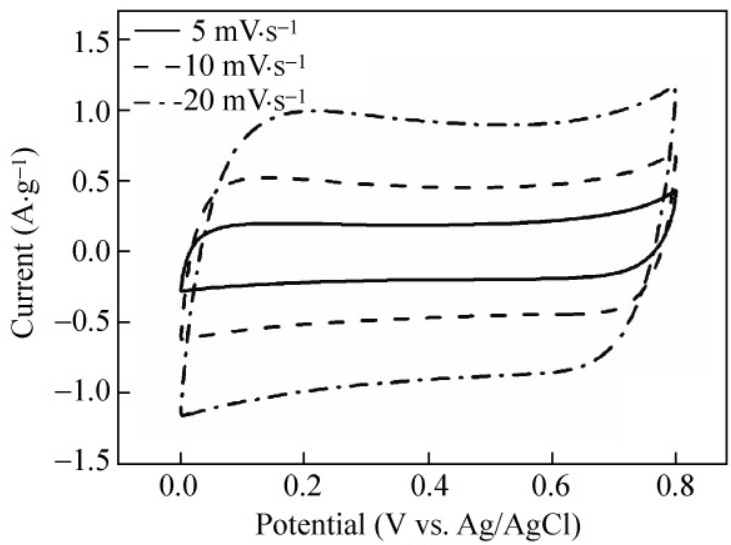

(a)

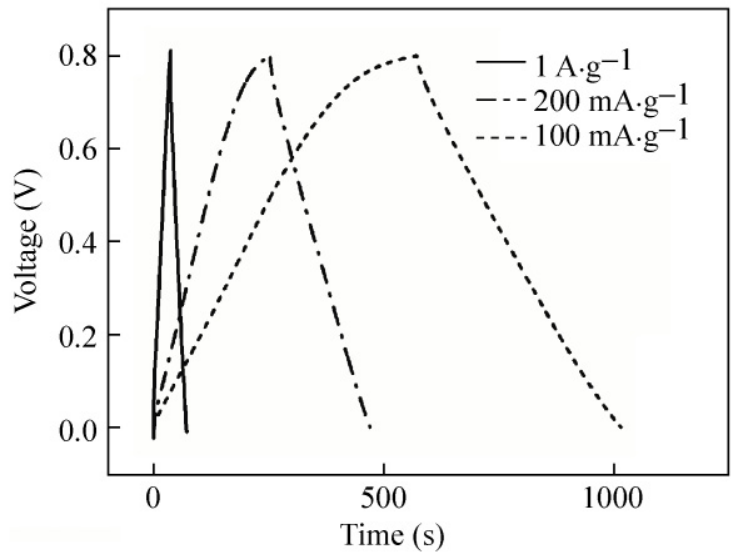

(c)

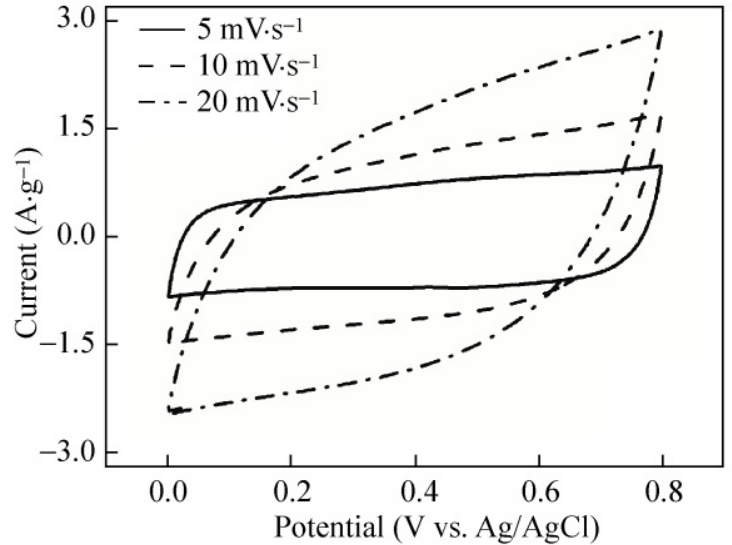

(b)

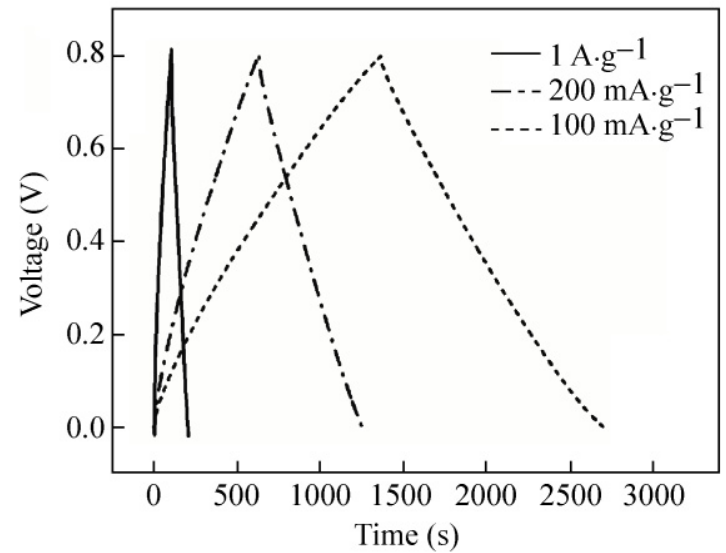

(d)

Figure 4 Cyclic voltammograms of electrodes made from (a) hierarchical carbon substrate and (b) $\mathrm{MnO}_{2} /$ carbon- 120 at potential sweep rates of 5,10 , and $20 \mathrm{mV} / \mathrm{s}$ in $1 \mathrm{~mol} / \mathrm{L} \mathrm{Na}_{2} \mathrm{SO}_{4}$ aqueous electrolyte at room temperature; Typical charge and discharge curves of the (c) carbon and (d) $\mathrm{MnO}_{2}$ /carbon-120 electrodes at different current densities of $0.1,0.2$, and $1 \mathrm{~A} / \mathrm{g}$ 


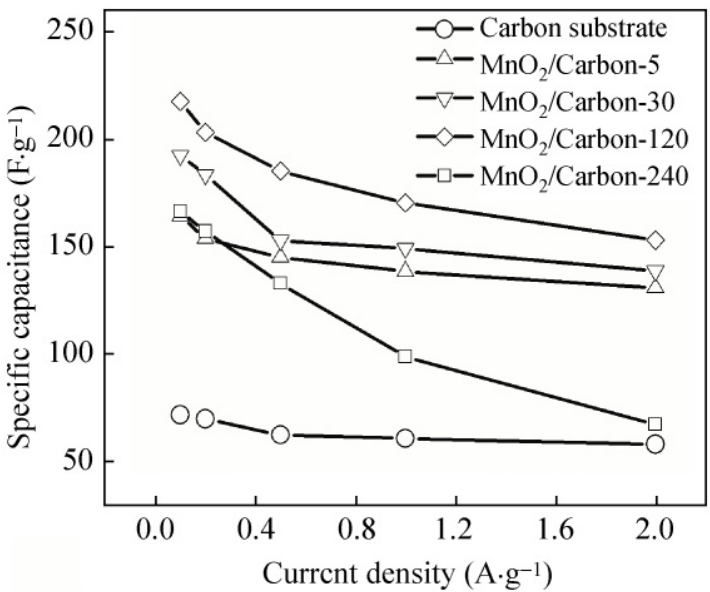

Figure 5 Gravimetric capacitance of the carbon substrate and composites with different $\mathrm{MnO}_{2}$ content measured at chargedischarge current densities of $0.1,0.2,0.5,1$, and $2 \mathrm{~A} / \mathrm{g}$ in $1 \mathrm{~mol} / \mathrm{L}$ $\mathrm{Na}_{2} \mathrm{SO}_{4}$ aqueous electrolyte at room temperature

capacitance of $164 \mathrm{~F} / \mathrm{g}$ at a current density of $0.1 \mathrm{~A} / \mathrm{g}$; $79 \%$ capacitance was retained $(130 \mathrm{~F} / \mathrm{g})$ at a current density of $2 \mathrm{~A} / \mathrm{g}$, exhibiting a good rate capability. The $\mathrm{MnO}_{2} /$ carbon-120 electrode, with 70 wt. $\% \mathrm{MnO}_{2}$ content, showed an even higher capacitance of $218 \mathrm{~F} / \mathrm{g}$ at $0.1 \mathrm{~A} / \mathrm{g}$ and good capacitance retention of $70 \%$ at $2 \mathrm{~A} / \mathrm{g}$. This value is about twice that of the capacitance of the $\mathrm{MnO}_{2} /$ carbon nanofoam composite prepared by a similar approach $(110 \mathrm{~F} / \mathrm{g}$ at $2 \mathrm{mV} / \mathrm{s})$ [34]. However, further increasing the $\mathrm{MnO}_{2}$ content resulted in a deterioration in the capacitance of the nanocomposites. For example, although the $\mathrm{MnO}_{2} /$ carbon-240 electrode has the highest $\mathrm{MnO}_{2}$ loading (83 wt.\%), its overall capacitance was only $166 \mathrm{~F} / \mathrm{g}$ at $0.1 \mathrm{~A} / \mathrm{g}$; only $40 \%$ of its capacitance was released at a current density of $2 \mathrm{~A} / \mathrm{g}$, which is similar to that for a pure $\mathrm{MnO}_{2}$ electrode. The deterioration in capacitance performance is due to the reduced electron conductivity (less residual carbon skeleton) and increased ion diffusion resistance (thicker $\mathrm{MnO}_{2}$ layer).

To further understand the galvanostatic charge and discharge results, EIS was used to quantify their conductive and diffusive behavior. Figure 6 shows Nyquist plots of the composite electrodes with different oxide content, all of which have a comparable ohmic resistance. Polarization resistance (or charge transfer resistance $R_{\mathrm{p}}$ ) of the electrode, shown in the high frequency region, increased gradually as the oxide content was increased. The $\mathrm{MnO}_{2} /$ carbon-240 electrode

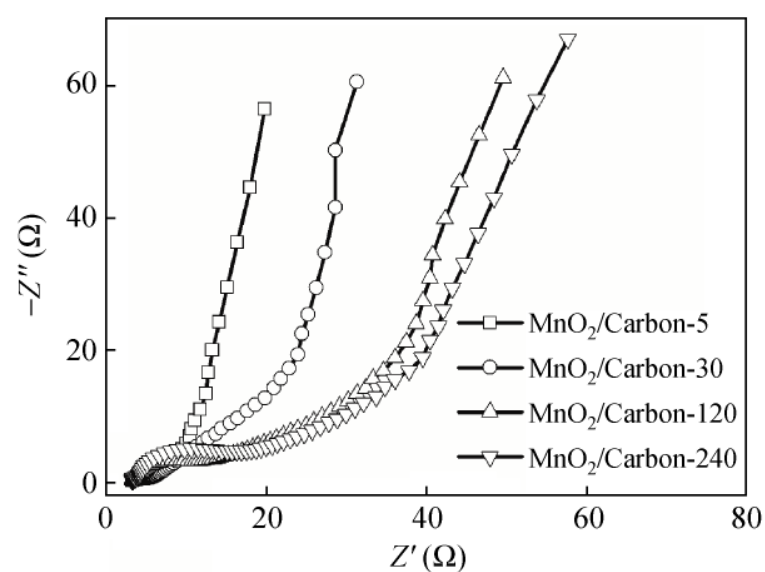

Figure 6 Nyquist plot from impedance spectroscopic analysis of the $\mathrm{MnO}_{2} /$ carbon-5 nanocomposite $(\square), \mathrm{MnO}_{2} /$ carbon-30 nanocomposite $(\circ), \mathrm{MnO}_{2} /$ carbon- 120 nanocomposite $(\triangle)$, and $\mathrm{MnO}_{2} /$ carbon-240 nanocomposite $(\nabla)$

has an $R_{\mathrm{p}}$ of $\sim 14 \Omega$ calculated from the diameter of the semicircle, which is significantly higher than that of the $\mathrm{MnO}_{2} /$ carbon-120, $\mathrm{MnO}_{2} /$ carbon-30, and $\mathrm{MnO}_{2} /$ carbon- 5 electrodes (10, 3, and $2 \Omega$, respectively). Assuming a bulk resistivity of $\mathrm{MnO}_{2}$ of $5 \times 10^{5} \Omega \mathrm{cm}$, a pure birnessite $\mathrm{MnO}_{2}$ electrode with the same thickness $(\sim 20 \mu \mathrm{m})$ as the composite electrode will have a resistance of $1000 \Omega$ [52]. It is clear that the carbon framework in the composites does serve as an effective conductive pathway, dramatically reducing the resistance. Note that with increasing $\mathrm{MnO}_{2}$ content, the slope of the Nyquist plot in the low frequency region decreased gradually, indicative of the increasing Warburg resistance (or diffusion resistance). These results are in good agreement with the $\mathrm{CV}$ and galvanostatic charge/discharge results, verifying that higher $\mathrm{MnO}_{2}$ content leads to larger charge transfer resistance and diffusion resistance. Therefore, to achieve good capacitance performance, it is necessary to maintain a connective carbon framework for good conductivity, and a high $\mathrm{MnO}_{2}$ content for high specific capacitance.

Besides the improved capacitance and good rate performance, the unique composite structure creates robust oxide/carbon interfaces, which endows the nanocomposites with outstanding cycling stability. Using $\mathrm{MnO}_{2}$ /carbon-120 as an example, Fig. 7 shows the charge-discharge cycles at a constant current density of $1 \mathrm{~A} / \mathrm{g}$ in $1 \mathrm{~mol} / \mathrm{L} \mathrm{Na}_{2} \mathrm{SO}_{4}$ electrolyte. The 


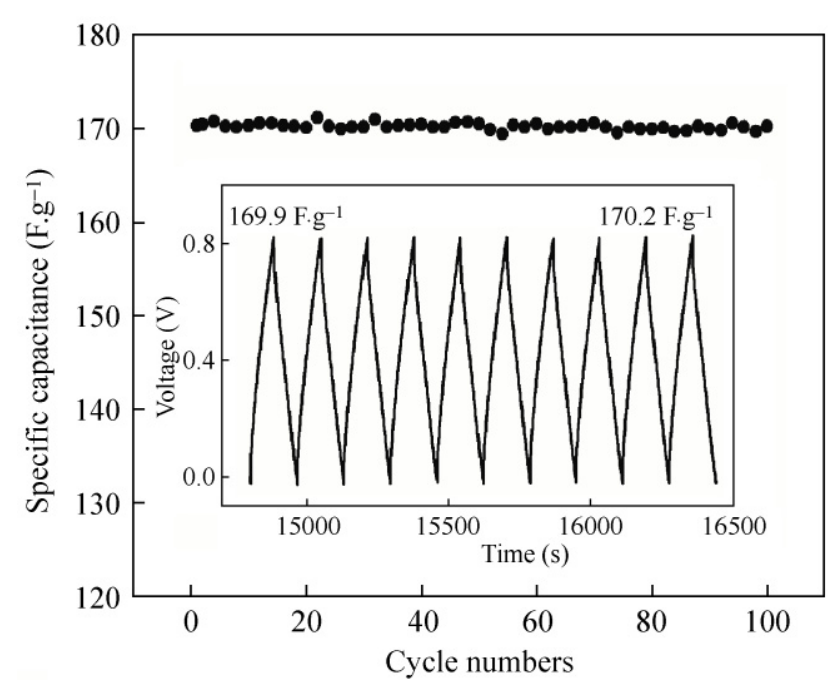

Figure 7 Cycling stability and typical charge and discharge curves (insert) of the $\mathrm{MnO}_{2} /$ carbon-120 nanocomposite at a current density of $1 \mathrm{~A} / \mathrm{g}$ in $1 \mathrm{~mol} / \mathrm{L}$ aqueous sodium sulfate electrolyte at room temperature

cycling performance is shown in the inset plot, which gives the GC plots from the 91st to 100th cycles. As shown, the electrode retained a very stable capacitance over 100 cycles (the capacitance decays by only $0.1 \%$ ), suggesting a good electrochemical cycling stability.

\section{Conclusions}

We have developed a general approach to synthesize $\mathrm{MnO}_{2} /$ carbon nanocomposites with hierarchically porous structure and controllable $\mathrm{MnO}_{2}$ loading using hierarchical carbon as the sacrificed substrate. Such unique porous substrates enable the formation of nanocomposites with high $\mathrm{MnO}_{2}$ loading and capacitance. An EIS study suggests that increasing the $\mathrm{MnO}_{2}$ loading also reduces the conductivity of the composites. Optimizing the $\mathrm{MnO}_{2}$ loading and conductivity of the nanocomposites provides high specific capacitance and excellent rate capability. The fundamental understanding gained in this work will promote the design and fabrication of highperformance supercapacitors for a large variety of applications.

\section{Acknowledgements}

This work was partially supported by the Center for
Molecularly Assembled Material Architectures for Solar Energy Production, Storage, and Carbon Capture, an Energy Frontier Research Center funded by the U.S. Department of Energy, Office of Science, Office of Basic Energy Sciences under award DE-SC0001342.

Electronic Supplementary Material: TGA measurements of the $\mathrm{MnO}_{2} /$ Carbon-10 nanocomposite and XRD spectra of the $\mathrm{MnO}_{2} /$ Carbon- 120 nanocomposite are available in the online version of this article at http://dx.doi.org/10.1007/s12274-010-0072-y.

\section{References}

[1] Kötz, R.; Carlen, M. Principles and applications of electrochemical capacitors. Electrochim. Acta. 2000, 45, 2483-2498.

[2] Conway, B. E. Electrochemical supercapacitors: Scientific fundamentals and technological applications; Kluwer Academic/Plenum: New York, 1999.

[3] Huggins, R. A.; Parsons, R. Supercapacitors. Phil. Trans. R. Soc. Lond. A. 1996, 354, 1555-1566.

[4] Liu, H.; Mao, C.; Lu, J.; Wang, D. Electronic power transformer with supercapacitors storage energy system. Electr. Pow. Syst. Res. 2009, 79, 1200-1208.

[5] Raymundo-Pińero, E.; Cadek, M.; Béguin, F. Tuning carbon materials for supercapacitors by direct pyrolysis of seaweeds. Adv. Funct. Mater. 2009, 19, 1032-1039.

[6] Arico, A. S.; Bruce, P.; Scrosati, B.; Tarascon, J. M.; van Schalkwijk, W. Nanostructured materials for advanced energy conversion and storage devices. Nat. Mater. 2005, 4, 366.

[7] Chmiola, J.; Yushin, G.; Gogotsi, Y.; Portet, C.; Simon, P.; Taberna, P. L. Anomalous increase in carbon capacitance at pore sizes less than 1 nanometer. Science 2006, 313, 17601763.

[8] Centeno, T. A.; Stoeckli, F. On the specific double-layer capacitance of activated carbons, in relation to their structural and chemical properties. J. Power Sources. 2006, 154, 314-320.

[9] Frackowiak, E. Carbon materials for supercapacitor application. Phys. Chem. Chem. Phys. 2007, 9, 1774-1785.

[10] Zheng, J. P.; Cygan, P. J.; Jow, T. R. Hydrous ruthenium oxide as an electrode material for electrochemical capacitors. J. Electrochem. Soc. 1995, 142, 2699-2703.

[11] Subramanian, V.; Hall, S. C.; Smith, P. H.; Rambabu, B. Mesoporous anhydrous $\mathrm{RuO}_{2}$ as a supercapacitor electrode material. Solid State Ionics. 2004, 175, 511-515.

[12] Wang, Y. G.; Wang, Z. D.; Xia, Y. Y. An asymmetric supercapacitor using $\mathrm{RuO}_{2} / \mathrm{TiO}_{2}$ nanotube composite and activated carbon electrodes. Electrochim. Acta. 2005, 50, 5641-5646. 
[13] Toupin, M.; Brousse, T.; Belanger, D. Influence of microstucture on the charge storage properties of chemically synthesized manganese dioxide. Chem. Mater. 2002, 14, 3946-3952.

[14] Pang, S. C.; Anderson, M. A.; Chapman, T. W. Novel electrode materials for thin-film ultracapacitors: Comparison of electrochemical properties of sol-gel-derived and electrodeposited manganese dioxide. J. Electrochem. Soc. 2000, 147, 444-450.

[15] Chang, J.; Lee, S.; Ganesh, T.; Mane, R. S.; Min, S.; Lee, W.; Han, S. H. Viologen-assisted manganese oxide electrode for improved electrochemical supercapacitors. J. Electroanal. Chem. 2008, 624, 167-173.

[16] Subramanian, V.; Zhu, H.; Wei, B. Nanostructured $\mathrm{MnO}_{2}$ : Hydrothermal synthesis and electrochemical properties as a supercapacitor electrode material. J. Power Sources. 2006, 159, 361-364.

[17] Liu, K. C.; Anderson, M. A. Porous nickel oxide/nickel films for electrochemical capacitors. J. Electrochem. Soc. 1996, 143, 124-130.

[18] Lang, J. W.; Kong, L. B.; Wu, W. J.; Luo, Y. C.; Kang, L. Synthesis, characterization, and electrochemical properties of $\mathrm{Ni}(\mathrm{OH})_{2} /$ ultra-stable Y zeolite composite. J. Mater. Sci. 2009, 44, 4466-4471.

[19] Lin, C.; Ritter, J. A.; Popov, B. N. Characterization of sol-gel-derived cobalt oxide xerogels as electrochemical capacitors. J. Electrochem. Soc. 1998, 145, 4097-4103.

[20] Reddy, R. N.; Reddy, R. G. Porous structured vanadium oxide electrode material for electrochemical capacitors. $J$. Power Sources. 2006, 156, 700-704.

[21] Hu, C. C.; Huang, C. M.; Chang, K. H. Anodic deposition of porous vanadium oxide network with high power characteristics for pseudocapacitors. J. Power Sources. 2008, 185, 1594-1597.

[22] Sato, Y.; Yomogida, K.; Nanaumi, T.; Kobayakawa, K.; Ohsawa, Y.; Kawai, M. Electrochemical behavior of activatedcarbon capacitor materials loaded with ruthenium oxide. Electrochem. Solid-State Lett. 2000, 3, 113-116.

[23] Kim, I. H.; Kim, J. H.; Lee, Y. H.; Kim, K. B. Synthesis and characterization of electrochemically prepared ruthenium oxide on carbon nanotube film substrate for supercapacitor applications. J. Electrochem. Soc. 2005, 152, A2170-A2178.

[24] Chen, Z.; Qin, Y.; Weng, D.; Xiao, Q.; Peng, Y.; Wang, X.; Li, H.; Wei, F.; Lu, Y. Design and synthesis of hierarchical nanowire composites for electrochemical energy storage. Adv. Funct. Mater. 2009, 19, 3420-3426.

[25] Wu, M.; Snook, G. A.; Chen, G. Z.; Fray, D. Redox deposition of manganese oxide on graphite for supercapacitors. $J$. Electrochem. Commun. 2004, 6, 499-504.
[26] Huang, X.; Yue, H.; Attia, A.; Yang, Y. Preparation and properties of manganese oxide/carbon composites by reduction of potassium permanganate with acetylene black. $J$. Electrochem. Soc. 2007, 154, A26.

[27] Ma, S. B.; Lee, Y. H.; Ahn, K. Y.; Kim, C. M.; Oh, K. H.; Kim, K. B. Spontaneously deposited manganese oxide on acetylene black in an aqueous potassium permanganate solution. J. Electrochem. Soc. 2006, 153, C27-C32.

[28] Zhu, S.; Zhou, H.; Hibino, M.; Honma, I.; Ichihara, M. Synthesis of $\mathrm{MnO}_{2}$ nanoparticles confined in ordered mesoporous carbon using a sonochemical method. Adv. Funct. Mater. 2005, 15, 381-386.

[29] Dong, X.; Shen, W.; Gu, J.; Xiong, L.; Zhu, Y.; Li, H.; Shi, H. J. $\mathrm{MnO}_{2}$-embedded-in-mesoporous-carbon-wall structure for use as electrochemical capacitors. J. Phys. Chem. B. 2006, 110, 6015-6019.

[30] Zhang, H.; Cao, G.; Wang, Z.; Yang, Y.; Shi, Z.; Gu, Z. Growth of manganese oxide nanoflowers on vertically-aligned carbon nanotube arrays for high-rate electrochemical capacitive energy storage. Nano Lett. 2008, 8, 2664-2668.

[31] Raymundo-Pińero, E.; Khomenko, V.; Frackowiak, E.; Béguin, F. Performance of manganese oxide/CNTs composites as electrode materials for electrochemical capacitors. J. Electrochem. Soc. 2005, 152, A229-A235.

[32] Lee, C. Y.; Tsai, H. M.; Chuang, H. J.; Li, S. Y.; Lin, P.; Tsen, T. Y. Characteristics and electrochemical performance of supercapacitors with manganese oxide-carbon nanotube nanocomposite electrodes. J. Electrochem. Soc. 2005, 152, A716-A720.

[33] Fan, Z.; Chen, J.; Wang, M.; Cui, K.; Zhou, H.; Kuang, Y. Preparation and characterization of manganese oxide/CNT composites as supercapacitive materials. Diam. Relat. Mater. 2006, 15, 1478-1483.

[34] Fischer, A. E.; Pettigrew, K. A.; Rolison, D. R.; Stroud, R. M.; Long, J. W. Incorporation of homogeneous, nanoscale $\mathrm{MnO}_{2}$ within ultraporous carbon structures via self-limiting electroless deposition: Implications for electrochemical capacitors. Nano Lett. 2007, 7, 281-286.

[35] Chu, H. Y.; Lai, Q. Y.; Wang, L.; Lu, J. F.; Zhao, Y. Preparation of $\mathrm{MnO}_{2} / \mathrm{WMNT}$ composite and $\mathrm{MnO}_{2} / \mathrm{AB}$ composite by redox deposition method and its comparative study as supercapacitive materials. Ionics. 2009, 16, 233-238.

[36] Wang, D. W.; Li, F.; Liu, M.; Lu, G.; Cheng, H. M. 3D aperiodic hierarchical porous graphitic carbon material for high-rate electrochemical capacitive energy storage. Angew. Chem. Int. Ed. 2008, 47, 373-376.

[37] Jiao, F.; Bruce, P. G. Mesoporous crystalline $\beta-\mathrm{MnO}_{2}$-reversible positive electrode for rechargeable lithium batteries. $A d v$. Mater. 2007, 5, 657-660. 
[38] Jin, X.; Zhou, Wu.; Zhang, S.; Chen, G. Z. Nanoscale microelectrochemical cells on carbon nanotubes. Small. 2007, 3, 1513-1517.

[39] Meng, Y.; Gu, D.; Zhang, F.; Shi, Y.; Yang, H.; Li, Z.; Yu, C.; Tu, B.; Zhao, D. Ordered mesoporous polymers and homologous carbon frameworks: Amphiphilic surfactant templating and direct transformation. Angew. Chem. Int. Ed. 2005, 44, 7053-7059.

[40] Feng, Q.; Sun, E. H.; Yanagisawa, K.; Yamasaki, N. Synthesis of birnessite-type sodium manganese oxides by solution reaction and hydrothermal methods. J. Ceram. Soc. Jpn. 1997, 105, 564-568.

[41] Shen, B.; Qin, L. Study on MSW catalytic combustion by TGA. Energy Convers. Manage. 2006, 47, 1429-1437.

[42] Liu, L.; Feng, Q.; Yanagisawa, K.; Wang, Y. Characterization of birnessite-type sodium manganese oxides prepared by hydrothermal reaction process. J. Mater. Sci. Lett. 2000, 19, 2047-2050.

[43] Feng, Q.; Yanagisawa, K.; Yamasaki, N. Synthesis of birnessite-type potassium manganese oxide. J. Mater. Sci. Lett. 1997, 16, 110-112.

[44] Sharma, R. K.; Oh, H. S.; Shul, Y. G.; Kim, H. Growth and characterization of carbon-supported $\mathrm{MnO}_{2}$ nanorods for supercapacitor electrode. Phy. Rev. B: Condens. Matter. 2008, 403, 1763-1769.

[45] Liu, R.; Shi, Y.; Wan, Y.; Meng, Y.; Zhang, F.; Gu, D.; Chen, Z.; Tu, B.; Zhao, D. Triconstituent co-assembly to ordered mesostructured polymer-silica and carbon-silica nanocomposites and large-pore mesoporous carbons with high surface areas. J. Am. Chem. Soc. 2006, 128, 11652-11662.

[46] Vol'khin, V. V.; Pogodina, O. A.; Leont'eva, G. V. Nonstoichiometric compounds based on manganese(III, IV) oxides with the birnessite structure. Russ. J. Gen. Chem. 2002, 72, 173-177.

[47] Devaraj, S.; Munichandraiah, N. Effect of crystallographic structure of $\mathrm{MnO}_{2}$ on its electrochemical capacitance properties. J. Phys. Chem. C. 2008, 112, 4406-4417.

[48] Luo, J.; Huang, A.; Park, S. H.; Suib, S. L.; O'Young, C. Crystallization of sodium $\beta$-birnessite and accompanied phase transformation. Chem. Mater. 1998, 10, 1561-1568.

[49] Hu, Q.; Lu, Y.; Meisner, G. P. Preparation of nanoporous carbon particles and their cryogenic hydrogen storage capacities. J. Phys. Chem. C. 2008, 112, 1516-1523.

[50] Brock, S. L.; Duan, N.; Tian, Z. R.; Giraldo, O.; Zhou, H.; Suib, S. L. A review of porous manganese oxide materials. Chem. Mater. 1998, 10, 2619-2628.

[51] Toupin, M.; Brousse, T.; Belanger, D. Charge storage mechanism of $\mathrm{MnO}_{2}$ electrode used in aqueous electrochemical capacitor. Chem. Mater. 2004, 16, 3184-3190.

[52] Guzman, R. N. D.; Awaluddin, A.; Shen, Y.; Tian, Z.; Suib, S. L.; Ching, S.; O'Young, C. Electrical resistivity measurements on manganese oxides with layer and tunnel structures: Birnessites, todorokites, and cryptomelanes. Chem. Mater. 1995, 7, 1286-1292. 